\title{
Genomic merit for reproductive traits. I: Estrous characteristics and fertility in Holstein heifers
}

\author{
Anderson Veronese, ${ }^{1}$ Odinei Marques, ${ }^{1}$ Rafael Moreira, ${ }^{1}$ Anna L. Belli, ${ }^{1}$ Rafael S. Bisinotto, ${ }^{1}$ Todd R. Bilby, ${ }^{2}$ \\ Francisco Peñagaricano, ${ }^{3}$ and Ricardo C. Chebel ${ }^{1,3 *}$ \\ ${ }^{1}$ Department of Large Animal Clinical Sciences, University of Florida, Gainesville 32610 \\ ${ }^{2}$ Merck Animal Health, Madison, NJ 07940 \\ ${ }^{3}$ Department of Animal Sciences, University of Florida, Gainesville 32610
}

\section{ABSTRACT}

Genetic selection of dairy cattle in the United States has included reproductive traits (daughter pregnancy rate, DPR; heifer conception rate, HCR), which is believed to have partly contributed to halting the decline in reproductive performance. The objectives of the current study were to evaluate the association among genomic merit for DPR (GDPR) and HCR (GHCR) with estrous characteristics measured by an automated device. Holstein heifers $(\mathrm{n}=1,005)$ were genotyped at $2 \mathrm{mo}$ of age and were classified into quartiles (Q1 = lowest, $\mathrm{Q} 4$ = highest) according to the GDPR and GHCR values of the study population. At 10 to 11 mo of age, heifers were fitted with a collar that recorded activity and rumination and determined the occurrence of estrus according to changes in activity and rumination compared with the individual's baseline values. Estrous characteristics of spontaneous estruses (SPE) and $\mathrm{PGF}_{2 \alpha}$-synchronized estruses (PGSE) were recorded. Heifers had their estrous cycle synchronized with $\mathrm{PGF}_{2 \alpha}$ and following detection of estrus received either artificial insemination or embryo transfer according to the herd's genetic selection program. Heifers in Q2 $(17.7 \pm 0.3 \mathrm{~h})$ of GHCR tended to have longer $\mathrm{SPE}$ than heifers in Q4 $(16.7 \pm 0.3 \mathrm{~h})$. The interaction between GDPR and GHCR was associated with the likelihood of activity peak $(0=$ no estrus, $100=$ maximum activity) $\geq 80$ at SPE because, among heifers in Q3 and Q4 of GHCR, those in Q1 of GDPR were less likely to have an activity peak $\geq 80$. Heifers in Q1 and Q2 of GDPR had reduced hazard of estrus within $7 \mathrm{~d}$ of the first $\mathrm{PGF}_{2 \alpha}$ treatment compared with heifers in Q4 of GDPR. Heifers in Q1 $(16.1 \pm 0.4 \mathrm{~h})$ of GDPR had shorter PGSE than heifers in Q2 $(17.6 \pm 0.4 \mathrm{~h})$ and Q4 $(17.4 \pm 0.4 \mathrm{~h})$ and tended to have shorter PGSE than

Received June 13, 2018.

Accepted January 30, 2019.

*Corresponding author: rcchebel@ufl.edu heifers in Q3 (17.4 $\pm 0.4 \mathrm{~h})$. Rumination nadir on the day of PGSE was greater for heifers in Q1 $(-30.1 \pm 0.9$ $\mathrm{min} / \mathrm{d})$ of GDPR compared with heifers in Q4 $(-33.7$ $\pm 0.9 \mathrm{~min} / \mathrm{d}$ ). Among heifers receiving only artificial insemination, those in Q1 of GHCR (adjusted hazard ratio $=0.65 ; 95 \%$ confidence interval $=0.48-0.88)$ became pregnant at a slower rate than heifers in Q4. Genomic merit for HCR was negatively associated with SPE but tended to be positively associated with hazard of pregnancy, whereas GDPR was positively associated with PGSE and hazard of estrus. Selection of dairy cattle for DPR and HCR may improve reproductive performance through different pathways, namely estrous characteristics and pregnancy establishment. Key words: genetic selection, automated estrous detection, estrous behavior

\section{INTRODUCTION}

Reproductive performance is extremely important to maximize the profitability of dairy operations (Giordano et al., 2012). Factors such as reproductive management, nutrition, health, and genetics affect reproductive outcomes directly or indirectly. Until the early 2000s, genetic selection of dairy breeds mainly focused on production traits while disregarding reproduction traits (Lucy, 2001). It is believed that this strategy contributed to the selection of cattle with reduced estrous expression and, consequently, reduced estrus detection and reproductive performance in modern dairy operations (Lopez et al., 2005). Although recent advancements in reproductive management facilitate fixed-time insemination of cows and heifers following ovulation synchronization protocols, even cattle subjected to such protocols have greater pregnancy per AI (P/AI) when they display estrus at the time of fixed time service (Lima et al., 2013). Additionally, estrous expression was associated with increased fertility and decreased pregnancy losses following timed AI and embryo transfer (ET; Pereira et al., 2016). 
Automated estrous detection monitoring devices (AED) that monitor changes in walking, activity, and rumination patterns have become more reliable for estrus detection and are being used in a growing number of dairies (Fricke et al., 2017). This technology records estrus events and estrous characteristics (duration, intensity, and so on) from a large number of animals in a uniform manner. Importantly, some of the estrous characteristics recorded (e.g., duration, lying behavior, intensity) have been positively associated with $\mathrm{P} / \mathrm{AI}$ in dairy cows (López-Gatius et al., 2005; Madureira et al., 2015; Silper et al., 2015; Burnett et al., 2017). Studies that evaluate the associations among genomic merit, physiological parameters, and estrous characteristics present a unique opportunity to understand how new strategies for genetic selection may affect estrous behavior and $\mathrm{P} / \mathrm{AI}$.

Estrous behavior is at least in part associated with differential gene expression in areas of the brain. Kommadath et al. (2010, 2011, 2013) and Woelders et al. (2014) assigned an estrus score to dairy cows based on estrous behaviors evaluated visually over multiple estrous cycles as previously described by Roelofs et al. (2005). Estrous score was associated with a substantial number of differentially expressed genes in different areas of the brain (Kommadath et al., 2010, 2011, 2013; Woelders et al., 2014), suggesting a possible presence of a genetic component driving estrous behavior in dairy cows. Ismael et al. (2015), however, reported heritability estimates for estrous duration and estrous strength measured by automated estrous detection systems that were low (0.02 and 0.05, respectively), which leads us to question whether selection for fertility traits in dairy cattle will in fact affect estrous characteristics. The estrous behaviors evaluated by Kommadath et al. (2010, 2011, 2013) and Woelders et al. (2014) included mounting activity and standing to be mounted, which are estrous signs positively associated with estrous duration and activity peak measured by an AED (Silper et al., 2015). Similarly, Ismael et al. (2015) demonstrated that genetic correlations between interval from calving to first insemination and both estrous duration and estrous strength were negative, which indicates that cows that were genetically predisposed to a shorter interval from calving to first insemination were also genetically predisposed to greater estrous duration and intensity. With the advancement of genomic selection tools, genetic gains of low-heritability traits in the US Holstein cattle population have been substantial (García-Ruiz et al., 2016). Despite improvements in the US Holstein population regarding reproduction traits such as the interval from calving to first AI, 21-d pregnancy rate (percentage of eligible cows that become pregnant within a 21-d period), and calving interval, there is a lack of information regarding the association among reproduction traits and estrous expression and characteristics.

Since the mid 2000s, genetic selection for dairy breeds has included reproduction traits such as daughter pregnancy rate (DPR), introduced in 2003 (VanRaden et al., 2003), and heifer conception rate (HCR), introduced in 2013 (https://queries.uscdcb.com/reference/ changes/chglst.cfm?run=1312). Heifer conception rate is a measure of the likelihood of pregnancy following AI of a bull's daughter compared with the contemporaneous population, whereas DPR is a measure of the hazard of pregnancy after calving (21-d pregnancy rate, days open) of a bull's daughters compared with the contemporaneous population. Hazard of pregnancy of lactating cows is dependent on health (Ribeiro et al., 2016) and resumption of ovarian cycles (Chebel and Santos, 2010) postpartum, estrus detection accuracy and efficiency (Chebel et al., 2006), and the likelihood of pregnancy after an insemination. We hypothesized that greater DPR is at least in part due to improved estrous expression and detection; thus, the use of heifers as a model could provide insights regarding this association while eliminating confounding effects inherent to the onset of lactation. Furthermore, we hypothesized that HCR, a phenotype independent of a heifer's ability to display estrus, could also be associated with estrous expression.

In the current study, we tested the hypotheses that genomic merit for DPR (GDPR) and genomic merit for HCR (GHCR) were associated with estrous characteristics and pregnancy establishment in dairy heifers. Therefore, the objective of the current study was to evaluate the associations among GDPR and GHCR and estrous characteristics, hazard of estrus, P/AI, and pregnancy loss of Holstein heifers.

\section{MATERIALS AND METHODS}

All procedures involving animals were approved by the animal care and use committee of the University of Florida (protocol no. 201609559). Figure 1A depicts study activities and data collection. Figure 1B depicts the numbers of heifers according to estrus detection strategy and breeding strategy (first and second services).

\section{Animals, Housing, and Management}

The data reported in this study were collected as part of an experiment to investigate the reproductive performance of heifers that had their estrous cycle 
synchronized with 2 different $\mathrm{PGF}_{2 \alpha}$ formulations and detected in estrus by 2 different systems. The experiment was conducted from March to December 2016 in a commercial dairy herd with approximately 4,200 replacement heifers located in north central Florida. A total of 1,019 heifers between 10 and 11 mo of age were enrolled in the study. Of the heifers enrolled, 1,005 heifers were genotyped within 2 mo of birth using a commercially available 50k SNP chip platform (Clarifide, Zoetis, Parsippany, NJ). We used the GDPR, GHCR, and genomic merit for milk yield values estimated within 2 mo of birth to prevent phenotypes related to reproductive performance from influencing the genomic estimates.

Starting at 12 mo of age heifers were weighed weekly, and those with $\mathrm{BW} \geq 340 \mathrm{~kg}$ were treated with $\mathrm{PGF}_{2 \alpha}$ and moved to a breeding pen (start of the reproductive program; d 0). Heifers were housed in dry lots with natural shade and no artificial heat abatement. Breed- ing pens had self-locking head stanchions on the feeding area. Heifers were fed twice daily $(0700$ and $1600 \mathrm{~h})$ a TMR formulated to meet or exceed the nutritional requirements of Holstein heifers weighing $\geq 340 \mathrm{~kg}$ of BW and gaining 800 to $1,000 \mathrm{~g} / \mathrm{d}$ (NRC, 2001). Daily average temperature, humidity, and precipitation from the meteorological station at the Gainesville airport, located approximately $64 \mathrm{~km}$ east of the dairy, were used to calculate daily temperature-humidity index. The percentage of days with temperature-humidity index $\geq 72$ (PctTHI72) and cumulative precipitation were recorded for each heifer from $\mathrm{d}-30$ to -1 , d 0 to 30 , and d 31 to 60 .

\section{AED and Estrous Characteristics}

At enrollment, an AED (Heat Rumination Long Distance, SCR Inc., Netanya, Israel) mounted on a collar was fitted on the left cranial area of the neck of all
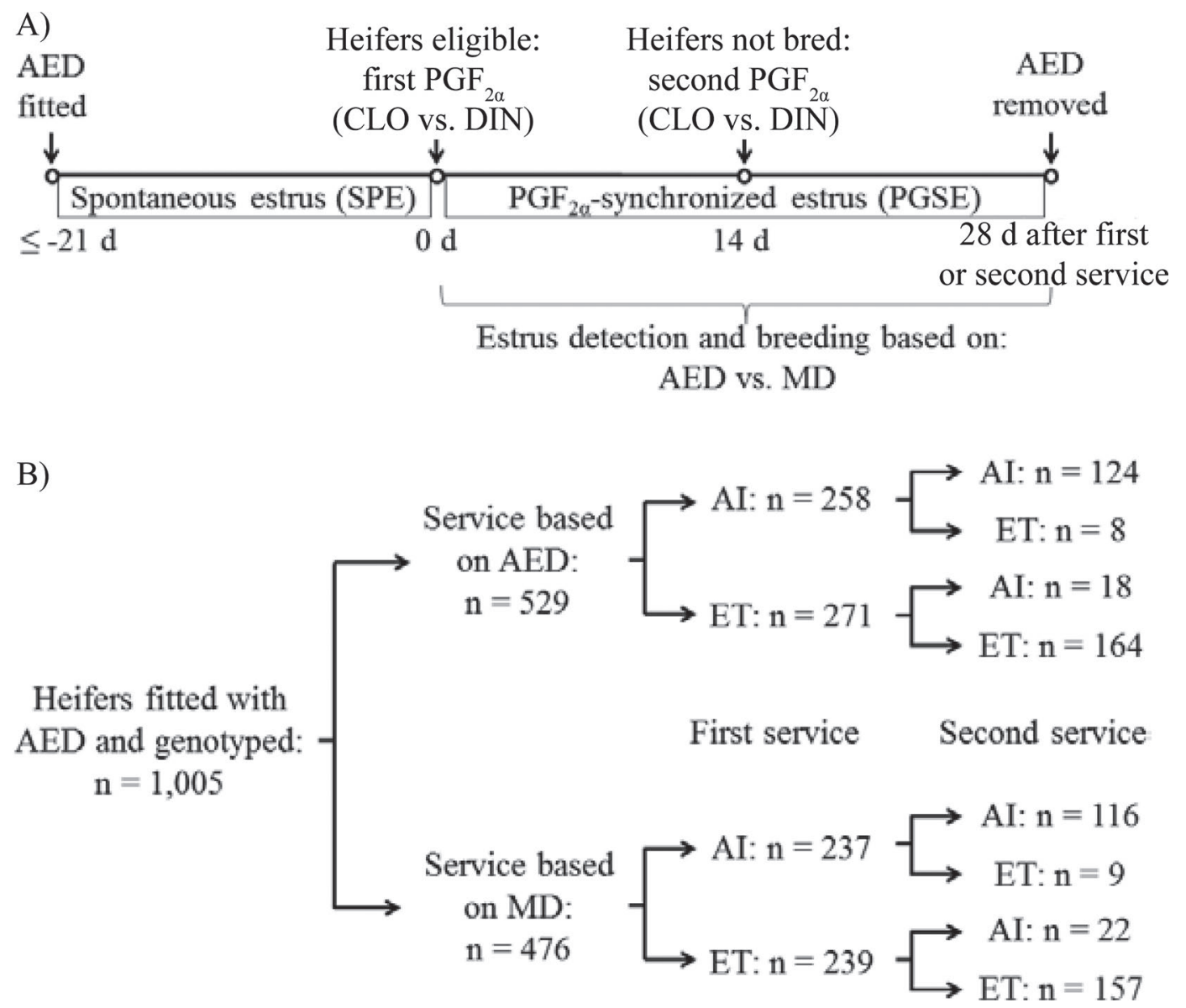

Figure 1. Depiction of (A) study activities and data collection and (B) number of heifers enrolled, serviced based on automated estrus detection (AED; Heat Rumination Long Distance, SCR Inc., Netanya, Israel) or mounting device (MD; Kamar Inc., Steamboat Springs, CO), and receiving AI or embryo transfer (ET) at first service (B). CLO = cloprostenol sodium (Estrumate, Merck Animal Health, Madison, NJ); DIN = dinoprost tromethamine (Lutalyse, Zoetis, Parsippany, NJ). 
heifers. The device determined activity through an accelerometer and rumination based on sounds of regurgitation and mastication through a microphone. Activity and rumination data were recorded in 2 -h intervals. Estrus was determined according to changes in patterns of activity and rumination within a 2 -h interval compared with the average activity and rumination of the same interval in the previous 5 and $7 \mathrm{~d}$, respectively (DataFlow2, SCR Inc.). Based on the intensity of changes in activity and rumination, an internal algorithm (DataFlow2) calculated the heat index $(0=$ no estrus to 100 $=$ maximum heat index). At 0600 and $1530 \mathrm{~h}$ each day, the activity and rumination patterns of heifers determined to be in estrus by the software were evaluated by the same member of the study team. On the day heifers were moved to the breeding pen, heifers with heat index $<50$, duration of estrus $<6 \mathrm{~h}$, and no change in rumination pattern were determined to have had changes in activity pattern caused by pen movement rather than an estrus event and were not inseminated. Heifers with heat index $\geq 70$ were considered to be in estrus. Retrospectively, a single member of the study team recorded heat index, activity peak ( $0=$ no change in activity, $100=$ maximum change in activity), and rumination nadir (maximum difference in rumination time within a 2-h interval during estrus compared with the average rumination of the same interval in the previous $7 \mathrm{~d}$ ) for all estrus events. Study personnel evaluated each activity graph individually and determined the time of onset (2-h interval when the activity threshold was surpassed), peak (2-h interval when the activity change was maximum), and end (2-h interval when the activity change was below the activity threshold) of estrus. Activity threshold was set at 3 -fold above the average activity for the same period in the previous $5 \mathrm{~d}$. Intervals from onset to the peak of estrus and from onset to the end of estrus were calculated. Characteristics of spontaneous estruses (SPE; estruses occurring before the start of the reproductive program) and $\mathrm{PGF}_{2 \alpha^{-}}$ synchronized estruses (PGSE; estruses occurring after the start of the reproductive program) were recorded. Automated estrous detection monitoring devices were removed from heifers that received a second service or when heifers were not detected in estrus within $28 \mathrm{~d}$ after the start of the reproductive program.

\section{Reproductive Management, Pregnancy Diagnoses, and Reproductive Data}

Once a week, heifers $\geq 12$ mo of age and $\geq 340 \mathrm{~kg}$ of BW were classified according to the interval from a previously recorded estrus by the AED as being in metestrus (d 0 to 3 ), early diestrus (d 4 to 6 ), mid diestrus (d 7 to 12), late diestrus (d 13 to 17), proestrus (d 18 to 23 ), and unknown ( $\mathrm{d} \geq 24$ or no estrus recorded). Heifers were then paired according to estrous cycle phase and were randomly allocated to treatments in a $2 \times 2$ design $\left(\mathrm{PGF}_{2 \alpha}\right.$ formulation and estrous detection treatment) according to a previously prepared randomized spreadsheet created in Excel (2010; Microsoft Corp., Redmond, WA). Heifers assigned to one treatment received $500 \mu \mathrm{g}$ of cloprostenol sodium (Estrumate; Merck Animal Health, Madison, NJ), and heifers assigned to the other treatment received $25 \mathrm{mg}$ of dinoprost tromethamine (Lutalyse; Zoetis, Parsippany, NJ). Heifers in metestrus were treated with $\mathrm{PGF}_{2 \alpha} 96 \mathrm{~h}$ later, and heifers in early diestrus, mid diestrus, and proestrus and heifers not detected in estrus were treated with $\mathrm{PGF}_{2 \alpha}$ on the same day. Fourteen days after the first $\mathrm{PGF}_{2 \alpha}$ treatment, heifers not detected in estrus received a second treatment with the same $\mathrm{PGF}_{2 \alpha}$ formulation. Heifers assigned to the mounting detection treatment were fitted with a mounting detection device (Kamar Heatmount Detectors; Kamar Products Inc., Zionsville, IN), which was evaluated daily at 0800 and 1600 h by 3 herdsmen who determined that the heifer was in estrus based on activation of the device. Heifers assigned to the AED treatment were not fitted with a mounting detection device and were deemed to be in estrus when the heat index recorded by the DataFlow2 was $\geq 70$. Heifers that had not been serviced by $18 \mathrm{~d}$ after the start of the reproductive program $(\mathrm{n}=11)$ and heifers not reinseminated in estrus and diagnosed open at pregnancy exam $(\mathrm{n}=19)$ were enrolled in an ovulation synchronization protocol for fixed-time AI and their data were not used in the current study $(\mathrm{n}=29)$.

Before the start of the reproductive program, heifers were selected to receive AI or ET based on the genetic selection program of the dairy - namely, genomic merit for milk yield, productive life, and net merit. A total of 495 heifers received AI for first service and 510 heifers received ET for first service, whereas 280 heifers received AI for second service and 338 heifers received ET for second service. Among heifers receiving first and second service based on detected estrus only, 476 heifers received only AI, 464 heifers received only ET, and 65 heifers received $\mathrm{AI}$ and $\mathrm{ET}$.

We examined all heifers for pregnancy by palpation per rectum of the uterine contents $38 \pm 3 \mathrm{~d}$ after estrus. Pregnant heifers were re-examined by palpation per rectum of the uterine contents $73 \pm 3 \mathrm{~d}$ after estrus. Pregnancy per service was calculated by dividing the number of heifers pregnant at the first and second pregnancy exams by the number of heifers inseminated. Pregnancy loss was calculated by dividing the number of heifers not pregnant at the second pregnancy exam 
by the number of heifers pregnant at the first pregnancy exam. Data regarding insemination sire, AI/ET technician, and reproductive outcomes were collected from the on-farm software (PCDART; Dairy Records Management System, Chapel Hill, NC).

\section{Statistical Analysis}

Data were analyzed using SAS version 9.3 (SAS Institute Inc., Cary, NC). Continuous variables were analyzed by ANOVA using the MIXED procedure of SAS. Data were evaluated for normality and homogeneity of residuals after fitting the model. Data violating the assumptions of normality were transformed. Rumination nadir values were multiplied by -1 and transformed to the natural $\log$. Thus, positive rumination nadir values were excluded $(\mathrm{SPE}=6, \mathrm{PGSE}=15)$. Among the 6 heifers with positive rumination nadir at SPE, 2 heifers from each of GDPR quartile (Q) 1, Q2, and Q3 were represented and 2, 2, 1, and 1 heifers from GHCR Q1, Q2, Q3, and Q4, respectively, were represented. Among the 15 heifers with positive rumination nadir at PGSE, 6, 5, 3, and 1 were heifers in GDPR Q1, $\mathrm{Q} 2, \mathrm{Q} 3$, and Q4, respectively, and 3, 5, 3, and 4 were heifers in GHCR Q1, Q2, Q3, and Q4, respectively. Outlier detection was performed, and rumination nadir transformed values $<2$ for SPE $(\mathrm{n}=4)$ and $<2.2$ for PGSE $(\mathrm{n}=4)$ were considered outliers and removed from the analysis. The intervals from the onset of SPE and PGSE to peak of activity were transformed to the square root. Activity peak and heat index were skewed to the right; therefore, we classified heifers as having activity peak $<80$ or $\geq 80$ and heat index $<80$ or $\geq 80$ because these cut-off values were associated with pregnancy after insemination (data not shown). Likelihood of activity peak $\geq 80$, heat index $\geq 80$, pregnancy at 38 and $73 \pm 3 \mathrm{~d}$ after estrus, and pregnancy loss between 38 and $73 \pm 3 \mathrm{~d}$ after estrus were analyzed by logistic regression using the GLIMMIX procedure. The hazard of estrus and hazard of pregnancy were analyzed by the Cox proportional hazard ratio using the PHREG procedure. Interval to an event (e.g., estrus, pregnancy) was analyzed by the Wilcoxon test of equality using the LIFETEST procedure.

Heifers were categorized into GDPR (Q1 $=-1.8$ to $0.8 ; \mathrm{Q} 2=0.9$ to $1.7 ; \mathrm{Q} 3=1.8$ to $2.5 ; \mathrm{Q} 4=2.6$ to 5.9 ) and $\mathrm{GHCR}$ (Q1 $=-2.1$ to $0.6 ; \mathrm{Q} 2=0.7$ to $1.4 ; \mathrm{Q} 3=$ 1.5 to $2.1 ; \mathrm{Q} 4=2.2$ to 5.5$)$ quartiles. Genomic merit for DPR and HCR and their interaction were included in all models. For each of the outcomes evaluated in the current study, univariate analyses were conducted to determine other explanatory variables that should be included in the multivariable model. Continuous variables (e.g., genomic merit estimate values for milk yield, PctTHI72, precipitation, estrous cycle day) were tested for their linear, quadratic, and cubic effects. Only explanatory variables with $P \leq 0.10$ were added to the multivariable models.

The multivariable statistical models that were used to analyze characteristics of SPE and PGSE, hazard of estrus within $7 \mathrm{~d}$ of $\mathrm{PGF}_{2 \alpha}$ treatment, hazard of estrus within $14 \mathrm{~d}$ after enrollment in the reproductive program, likelihood of pregnancy and pregnancy loss after the first and second service, and hazard of pregnancy from the start of the reproductive program are listed in Supplemental Table S1 (https://doi.org/10.3168/jds .2018-15205). Heifers that had been detected in estrus by the AED $>26 \mathrm{~d}$ before the $\mathrm{PGF}_{2 \alpha}$ treatment $(\mathrm{n}=$ 10) and heifers not detected in estrus $\leq 168 \mathrm{~h}$ after the $\mathrm{PGF}_{2 \alpha}$ treatment $(\mathrm{n}=106)$ were not included in the analysis of PGSE characteristics. Hazard of estrus was analyzed based on the day of the first $\mathrm{PGF}_{2 \alpha}$ treatment, for which heifers that displayed estrus $>168 \mathrm{~h}$ after the $\mathrm{PGF}_{2 \alpha}$ treatment were censored, and based on the day of the start of the reproductive program, for which heifers that did not display estrus by $14 \mathrm{~d}$ after the start of the reproductive program were censored.

For each of the statistical models, collinearity was tested using the REG procedure with the collin and VIF functions. Variables with variance inflation factors $\geq 1.5$ were considered collinear, but none of the explanatory variables met this criterion. In all models, a backward stepwise elimination procedure was adopted and variables with $P>0.10$ were removed until all variables that remained in the model had $P \leq 0.10$. To control for familywise error rate due to multiple comparison, the Tukey-Kramer method was applied, and statistical significance was considered at adjusted $P \leq 0.05$ and a tendency was considered when $0.05<$ adjusted $P \leq 0.10$. Data are reported as least squares means \pm standard error of the means unless otherwise stated.

\section{RESULTS}

\section{Characteristics of the Study Population}

Mean age and BW at the start of the reproductive program were $377 \pm 6 \mathrm{~d}$ and $384 \pm 28 \mathrm{~kg}$, respectively. Mean $( \pm \mathrm{SD})$ GDPR value of the study population was $1.65 \pm 1.29$ (range: -1.8 to 5.9 ; Figure 2), and mean $( \pm \mathrm{SD})$ GHCR value of the study population was 1.34 \pm 1.11 (range: -2.1 to 5.5 ; Figure 2). Spearman's coefficient of rank correlation between GDPR and GHCR in the study population was $0.455(95 \% \mathrm{CI}=0.405$ to $0.503, P<0.01 ;$ Figure 2). The correlation between 

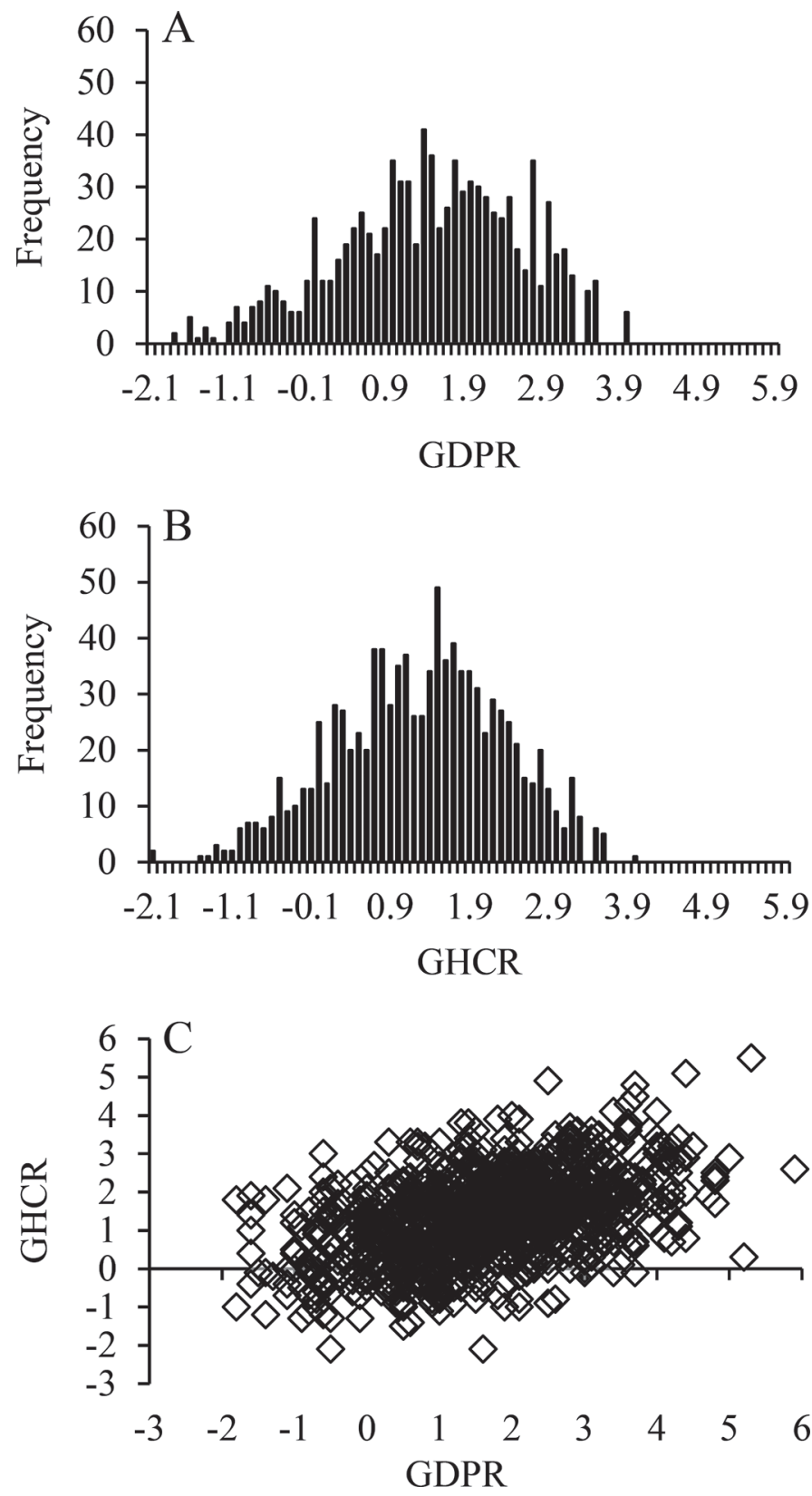

Figure 2. (A) Distribution of genomic merit for daughter pregnancy rate $(\mathrm{GDPR})$ values in the study population. Mean $( \pm \mathrm{SD})$ GDPR $=1.65 \pm 1.29 ;$ range $=-1.8$ to 5.9 . (B) Distribution of genomic merit for heifer conception rate (GHCR) values in the study population. Mean $( \pm \mathrm{SD}) \mathrm{GHCR}=1.34 \pm 1.1$; range $=-2.1$ to 5.5 . $(\mathrm{C})$ Correlation of GDPR and GHCR. Spearman's coefficient of rank correlation $=0.46(95 \% \mathrm{CI}=0.41-0.50 ; P<0.01)$.

GDPR and genomic merit for milk yield was -0.366 $(95 \% \mathrm{CI}=-0.418$ to $-0.312, P<0.01)$, and the genomic merit for milk yield according to GDPR quartiles was $\mathrm{Q} 1=1,243.3 \pm 477.1, \mathrm{Q} 2=990.8 \pm 471.8, \mathrm{Q} 3=$ $941.9 \pm 484.1$, and $\mathrm{Q} 4=724.1 \pm 457.0 \mathrm{~kg}$. Spearman's coefficient of rank correlation between GHCR

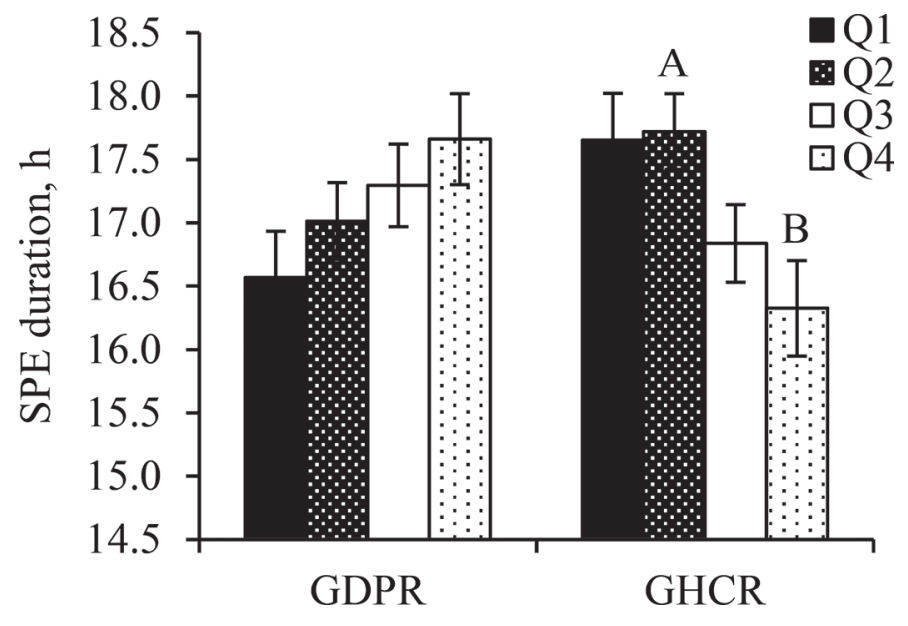

Figure 3. Association between genomic merit for daughter pregnancy rate (GDPR) and genomic merit for heifer conception rate (GHCR) and duration of spontaneous estrus (SPE). GDPR: Q1 = -1.8 to $0.8, \mathrm{Q} 2=0.9$ to $1.7, \mathrm{Q} 3=1.8$ to 2.5 , and $\mathrm{Q} 4=2.6$ to 5.9 . GHCR: Q1 $=-2.1$ to $0.6, \mathrm{Q} 2=0.7$ to $1.4, \mathrm{Q} 3=1.5$ to 2.1 , and $\mathrm{Q} 4$ $=2.2$ to 5.5. Effects of GDPR $(P=0.24)$, GHCR $(P=0.05)$, and the interaction between GDPR and GHCR $(P=0.46)$. Q $=$ quartile (Q1 $=$ lowest. Q4 = highest). Error bars represent the SEM. Means with different letters $(\mathrm{A}, \mathrm{B})$ tended to differ $(0.05<P \leq 0.10)$.

and genomic merit for milk yield was -0.074 (95\% CI $=-0.135$ to $-0.013, P=0.02)$, and the genomic merit for milk yield according to GHCR quartiles was Q1 = $1,064.5 \pm 467.8, \mathrm{Q} 2=947.3 \pm 534.9, \mathrm{Q} 3=967.0 \pm$ 549.6 , and $\mathrm{Q} 4=935.3 \pm 461.8 \mathrm{~kg}$.

\section{Association Among GDPR and GHCR and Characteristics of SPE}

Genomic merit for DPR was not $(P=0.24)$ associated with the duration of the SPE, but GHCR was $(P$ $=0.05)$ associated with the duration of the SPE. There was a tendency $(P=0.10)$ for heifers in Q2 for GHCR to have longer SPE than heifers in Q4, whereas heifers in Q1 and Q3 did not $(P \geq 0.21)$ differ from each other or from heifers in Q2 and Q4 (Figure 3). The interaction between GDPR and GHCR was not $(P=0.46)$ associated with the duration of the SPE. The PctTHI72 from $\mathrm{d}-30$ to -1 was (linear: $-1.33 \pm 0.45, P<0.01$ ) negatively associated with the duration of SPE.

The interval from onset of estrus to peak of activity was not associated with GDPR $(\mathrm{Q} 1=7.5 \pm 1.1$, $\mathrm{Q} 2=7.0 \pm 1.1, \mathrm{Q} 3=7.3 \pm 1.1$, and $\mathrm{Q} 4=7.9 \pm$ $1.1 \mathrm{~h} ; P=0.30)$, GHCR $(\mathrm{Q} 1=7.5 \pm 1.1, \mathrm{Q} 2=7.7$ $\pm 1.1, \mathrm{Q} 3=7.4 \pm 1.1$, and $\mathrm{Q} 4=7.0 \pm 1.1 \mathrm{~h} ; P=$ $0.30)$, and the interaction between GDPR and GHCR $(P=0.47)$. Genomic merit for milk yield was (linear: $-0.0001 \pm 0.0001 ; P<0.01)$ negatively associated with the interval from onset of estrus to peak of activity. The 
PctTHI72 from d -30 to -1 was (linear: $-0.25 \pm 0.07$, $P<0.01)$ negatively associated with the interval from onset of estrus to peak of activity.

Rumination nadir on the day of SPE was not associated with GDPR $(\mathrm{Q} 1=-33.6 \pm 1.1, \mathrm{Q} 2=-34.4 \pm$ $1.1, \mathrm{Q} 3=-36.1 \pm 1.2$, and $\mathrm{Q} 4=-33.5 \pm 1.1 \mathrm{~min} / \mathrm{d} ; P$ $=0.34), \operatorname{GHCR}(\mathrm{Q} 1=-35.1 \pm 1.2, \mathrm{Q} 2=-34.1 \pm 1.1$, $\mathrm{Q} 3=-35.4 \pm 1.1$, and $\mathrm{Q} 4=-33.0 \pm 1.1 \mathrm{~min} / \mathrm{d} ; P=$ $0.46)$, and the interaction between GDPR and GHCR $(P=0.46)$. Genomic merit for milk yield was (linear: $-0.0001 \pm 0.0001 ; P=0.03)$ negatively associated with rumination nadir at SPE. There was (linear: $0.07 \pm$ $0.02, P<0.01$; quadratic: $-0.005 \pm 0.002, P=0.02)$ a positive association between cumulative precipitation from $\mathrm{d}-30$ to -1 and rumination nadir.

An interaction between GDPR and GHCR was detected $(P=0.04)$ for the likelihood of activity peak $\geq 80$; among heifers in Q3 and Q4 of GHCR, those in Q1 of GDPR were less likely to have activity peak $\geq 80$ (Figure 4). Cumulative precipitation from $\mathrm{d}-30$ to -1 was (linear: $0.32 \pm 0.17, P=0.05$; quadratic: $-0.03 \pm$ $0.02, P=0.04)$ positively associated with the likelihood of activity peak $\geq 80$.

The likelihood of heat index $\geq 80$ at SPE was not associated with GDPR (Q1 $=91.2 \pm 2.0, \mathrm{Q} 2=94.9$ $\pm 1.4, \mathrm{Q} 3=92.8 \pm 1.8$, and $\mathrm{Q} 4=93.5 \pm 1.6 \% ; P=$ $0.48)$, GHCR $(\mathrm{Q} 1=94.5 \pm 1.5, \mathrm{Q} 2=93.9 \pm 1.5, \mathrm{Q} 3$ $=92.5 \pm 1.7$, and $\mathrm{Q} 4=91.1 \pm 1.9 \% ; P=0.50)$ or the interaction between GDPR and GHCR $(P=0.76)$.

\section{Association Among GDPR and GHCR and Characteristics of PGSE}

Genomic merit for DPR was $(P=0.01)$ associated with the hazard of estrus within $7 \mathrm{~d}$ of the first $\mathrm{PGF}_{2 \alpha}$ treatment $[\mathrm{Q} 1$ - adjusted hazard ratio $(\mathrm{AHR})=0.69$, $95 \% \mathrm{CI}=0.55-0.86 ; \mathrm{Q} 2-\mathrm{AHR}=0.74,95 \% \mathrm{CI}=$ $0.60-0.92 ; \mathrm{Q} 3-\mathrm{AHR}=0.84,95 \% \mathrm{CI}=0.68-1.04 ;$ and Q4 is the referent value to which Q1, Q2, and Q3 are compared]. The median interval from the first $\mathrm{PGF}_{2 \alpha}$ treatment to the first detected estrus was $62.5,62,61$, and $52 \mathrm{~h}$ for heifers in Q1, Q2, Q3, and Q4 of GDPR, respectively (Figure 5). Genomic merit for $\operatorname{HCR}(P=$ $0.74)$ and the interaction between GDPR and GHCR $(P=0.80)$ were not associated with the hazard of estrus within $7 \mathrm{~d}$ of the first $\mathrm{PGF}_{2 \alpha}$ treatment. Genomic merit for milk yield was (linear: $-0.0003, P=0.15$, quadratic: $0.0000002, P=0.05)$ negatively associated with hazard of estrus within $7 \mathrm{~d}$ of the first $\mathrm{PGF}_{2 \alpha}$ treatment. Hazard of estrus within $7 \mathrm{~d}$ of the first $\mathrm{PGF}_{2 \alpha}$ treatment was positively associated with estrous cycle day at $\mathrm{PGF}_{2 \alpha}$ treatment (linear: $0.82 \pm 0.13, P<$ 0.01 ; quadratic: $-0.05 \pm 0.01, P<0.01$; cubic: $0.001 \pm$

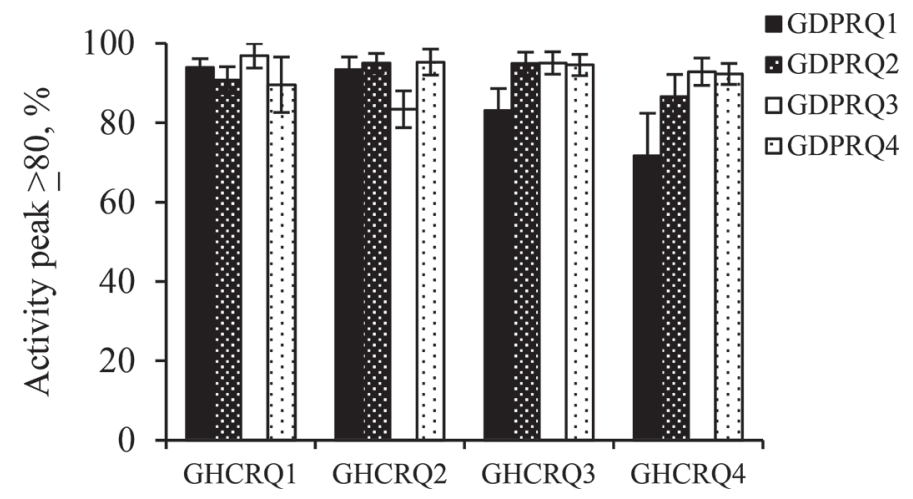

Figure 4. Probability of activity peak $\geq 80$ at spontaneous estrus (SPE) according to genomic merit for daughter pregnancy rate $(\mathrm{GDPR})$ and heifer conception rate (GHCR). GDPR: $\mathrm{Q} 1=-1.8$ to $0.8, \mathrm{Q} 2=0.9$ to $1.7, \mathrm{Q} 3=1.8$ to 2.5 , and $\mathrm{Q} 4=2.6$ to 5.9 . GHCR: $\mathrm{Q} 1$ $=-2.1$ to $0.6, \mathrm{Q} 2=0.7$ to $1.4, \mathrm{Q} 3=1.5$ to 2.1 , and $\mathrm{Q} 4=2.2$ to 5.5 . Effects of GDPR $(P=0.21)$, GHCR $(P=0.20)$, and the interaction between GDPR and GHCR $(P=0.04)$. Q $=$ quartile (Q1 = lowest, $\mathrm{Q} 4$ $=$ highest). Error bars represent the SEM.

0.001, $P<0.01)$. There was a tendency for PctTHI72 from d 0 to 30 to be associated with the hazard of estrus within $7 \mathrm{~d}$ of the first $\mathrm{PGF}_{2 \alpha}$ treatment (linear: $1.04 \pm 0.58, P=0.07$; quadratic: $-0.96 \pm 0.51, P=$ $0.06)$.

Hazard of estrus within $14 \mathrm{~d}$ of the start of the reproductive program was $(P<0.01)$ associated with GDPR $[\mathrm{Q} 1-\mathrm{AHR}=0.69,95 \% \mathrm{CI}=0.56-0.86 ; \mathrm{Q} 2$

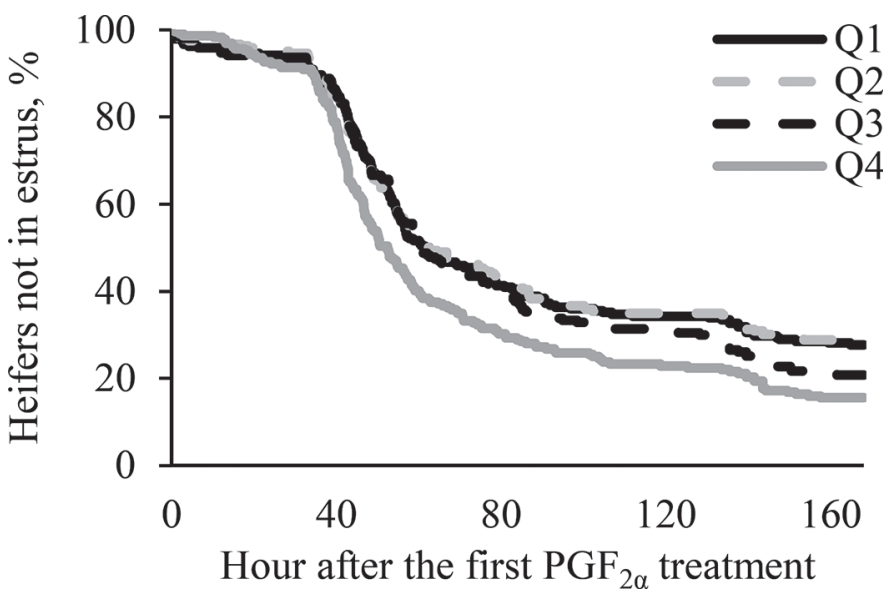

Figure 5. Association between genomic merit for daughter pregnancy rate (GDPR) and interval from the first $\mathrm{PGF}_{2 \alpha}$ treatment to the first estrus detected. GDPR: Q1 $=-1.8$ to $0.8, \mathrm{Q} 2=0.9$ to 1.7 , Q3 $=1.8$ to 2.5 , and $\mathrm{Q} 4=2.6$ to 5.9 . Mean $( \pm \mathrm{SEM})$ and median, respectively, intervals from the first $\mathrm{PGF}_{2 \alpha}$ treatment to the first detected estrus: $\mathrm{Q} 1=81.6 \pm 3.5$ and $62.5, \mathrm{Q} 2=66.4 \pm 2.0$ and $62, \mathrm{Q} 3=71.6$ \pm 3.1 and 61 , and $\mathrm{Q} 4=65.4 \pm 2.7$ and $52 \mathrm{~h}$. Percentage of heifers censored at $7 \mathrm{~d}$ after the first $\mathrm{PGF}_{2 \alpha}$ treatment: $\mathrm{Q} 1=25.3, \mathrm{Q} 2=25.1$, $\mathrm{Q} 3=17.3$, and $\mathrm{Q} 4=14.4 \%$. Effect of GDPR $(P<0.01) . \mathrm{Q}=$ quartile (Q1 = lowest, $\mathrm{Q} 4=$ highest $)$. 


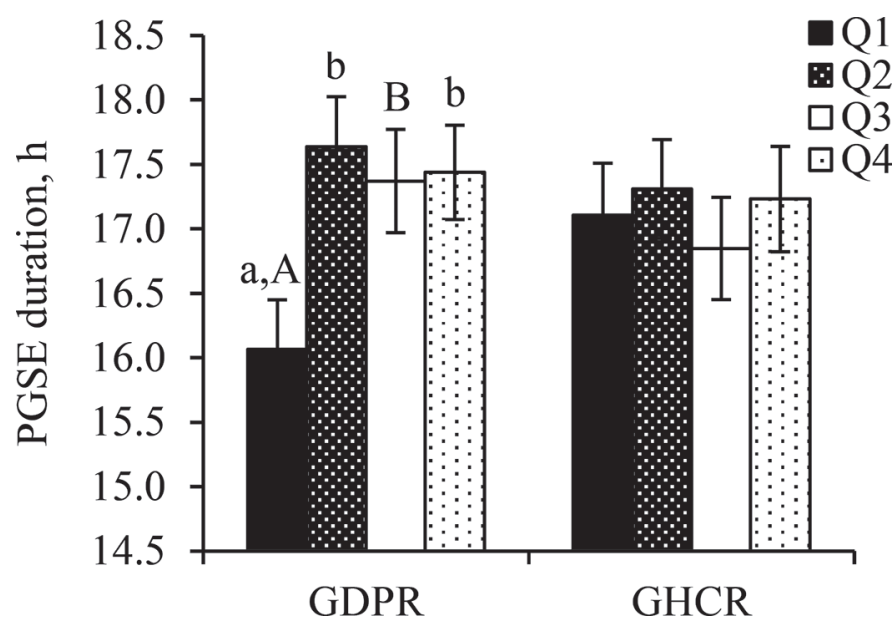

Figure 6. Duration of $\mathrm{PGF}_{2 \alpha}$-synchronized estrus (PGSE) according to genomic merit for daughter pregnancy rate (GDPR) and genomic merit for heifer conception rate (GHCR). GDPR: Q1 $=-1.8$ to $0.8, \mathrm{Q} 2=0.9$ to $1.7, \mathrm{Q} 3=1.8$ to 2.5 , and $\mathrm{Q} 4=2.6$ to 5.9 . GHCR: $\mathrm{Q} 1$ $=-2.1$ to $0.6, \mathrm{Q} 2=0.7$ to $1.4, \mathrm{Q} 3=1.5$ to 2.1 , and $\mathrm{Q} 4=2.2$ to 5.5 . Effects of GDPR $(P=0.02)$, GHCR $(P=0.85)$, and the interaction between GDPR and GHCR $(P=0.57)$. Q = quartile $(\mathrm{Q} 1=$ lowest, $\mathrm{Q} 4$ $=$ highest). Error bars represent the SEM. Means with different lowercase letters $(\mathrm{a}, \mathrm{b})$ differ $(P \leq 0.05)$. Means with different uppercase letters $(\mathrm{A}, \mathrm{B})$ tended to differ $(0.05<P \leq 0.10)$.

$-\mathrm{AHR}=0.73,95 \% \mathrm{CI}=0.60-0.89 ; \mathrm{Q} 3-\mathrm{AHR}=0.80$, $95 \% \mathrm{CI}=0.65-0.99$; and $\mathrm{Q} 4$ is the referent value to which Q1, Q2, and Q3 are compared]. Heifers in Q4 for GDPR were detected in estrus $96.1 \pm 6.6 \mathrm{~h}$ after the start of the reproductive program, followed by heifers in Q3 $(115.7 \pm 7.6 \mathrm{~h})$ and heifers in Q2 $(133.0 \pm 7.8 \mathrm{~h})$ and Q1 (130.7 $\pm 7.8 \mathrm{~h})$. Additionally, 17.1, 16.4, 15.7, and $8.4 \%$ of heifers in Q1, Q2, Q3, and Q4 of GDPR, respectively, were censored at $14 \mathrm{~d}$ after the start of the reproductive program. Genomic merit for HCR $(P=0.82)$ and the interaction between GDPR and GHCR $(P=0.84)$ were not associated with the hazard of estrus within $14 \mathrm{~d}$ after the start of the reproductive program. Genomic merit for milk yield tended (linear: $-0.0003 \pm 0.0002, P=0.15$; quadratic: $0.0000002 \pm$ $0.0000001, P=0.08)$ to be negatively associated with the hazard of estrus within $14 \mathrm{~d}$ after the start of the reproductive program. Estrous cycle day at the start of the reproductive program was (linear: $0.30 \pm 0.03, P<$ 0.01 ; quadratic: $-0.008 \pm 0.001, P<0.01)$ positively associated with the hazard of estrus within $14 \mathrm{~d}$ after the start of the reproductive program.

Genomic merit for DPR $(P=0.02)$ was associated with the duration of the PGSE because heifers in Q1 had $(P \leq 0.05)$ shorter PGSE than heifers in Q2 and Q4 and tended $(P=0.09)$ to have shorter PGSE than heifers in Q3 (Figure 6). Genomic merit for $\operatorname{HCR}(P=$ $0.85)$ and the interaction between GDPR and GHCR
$(P=0.57)$ were not associated with duration of PGSE (Figure 6). Estrous cycle day at $\mathrm{PGF}_{2 \alpha}$ treatment was (linear: $0.76 \pm 0.22, P<0.001$; quadratic: $-0.02 \pm$ $0.01, P=0.02)$ positively associated with the duration of PGSE. The PctTHI72 from d 0 to 30 was (linear: $6.93 \pm 2.80, P=0.01$; quadratic: $-6.34 \pm 2.47, P=$ $0.01)$ associated with the duration of PGSE.

There were no associations between GDPR (Q1 = $7.2 \pm 0.2, \mathrm{Q} 2=7.8 \pm 0.2, \mathrm{Q} 3=7.6 \pm 0.2$, and $\mathrm{Q} 4=$ $7.8 \pm 0.2 \mathrm{~h} ; P=0.37)$, GHCR $(\mathrm{Q} 1=7.6 \pm 0.2, \mathrm{Q} 2=$ $7.8 \pm 0.2, \mathrm{Q} 3=7.4 \pm 0.2$, and $\mathrm{Q} 4=7.6 \pm 0.2 \mathrm{~h} ; P=$ 0.79 ), and the interaction between GDPR and GHCR $(P=0.23)$ and the interval from onset of PGSE to activity peak. There was (linear: $0.127 \pm 0.032, P<$ 0.01 ; quadratic: $-0.004 \pm 0.001, P<0.01)$ a positive association between estrous cycle day at $\mathrm{PGF}_{2 \alpha}$ treatment and the interval from onset of PGSE to activity peak.

Genomic merit for DPR was $(P=0.02)$ associated with rumination nadir on the day of PGSE because heifers in $\mathrm{Q} 1$ had $(P=0.02)$ greater rumination nadir on the day of PGSE than Q4 heifers (Figure 7). Genomic merit for HCR $(P=0.58)$ and the interaction between GDPR and GHCR $(P=0.22)$ were not associated with rumination nadir on the day of PGSE (Figure 7). Estrous cycle phase on the day of treatment with PGF $_{2 \alpha}$ (linear: $0.018 \pm 0.003, P<0.01$ ) and cumulative precipitation from d 0 to 30 (linear: $0.016 \pm 0.005, P<$

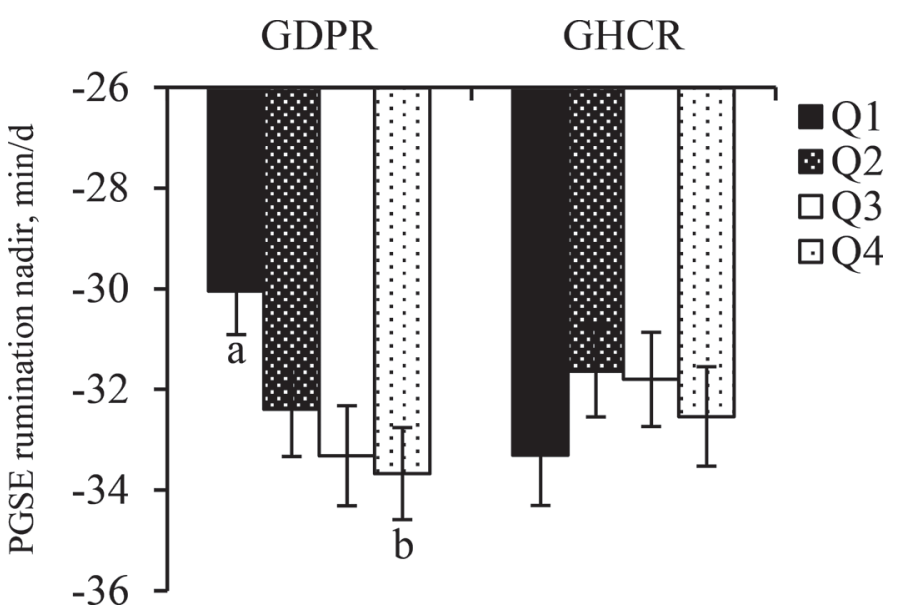

Figure 7. Rumination nadir at $\mathrm{PGF}_{2 \alpha}$-synchronized estrus (PGSE) according to genomic merit for daughter pregnancy rate (GDPR) and genomic merit for heifer conception rate (GHCR). GDPR: Q1 $=-1.8$ to $0.8, \mathrm{Q} 2=0.9$ to $1.7, \mathrm{Q} 3=1.8$ to 2.5 , and $\mathrm{Q} 4=2.6$ to 5.9 . GHCR: $\mathrm{Q} 1=-2.1$ to $0.6, \mathrm{Q} 2=0.7$ to $1.4, \mathrm{Q} 3=1.5$ to 2.1 , and $\mathrm{Q} 4=2.2$ to 5.5. Effects of GDPR $(P=0.02)$, GHCR $(P=0.58)$, and the interaction between GDPR and GHCR $(P=0.22) . \mathrm{Q}=$ quartile $(\mathrm{Q} 1$ = lowest, $\mathrm{Q} 4=$ highest). Error bars represent the SEM. Means with different lowercase letters $(\mathrm{a}, \mathrm{b})$ differ $(P \leq 0.05)$. 
0.01) were negatively associated with rumination nadir on the day of PGSE.

The interaction between GDPR and GHCR was $(P=0.04)$ associated with the likelihood of activity peak $\geq 80$ at PGSE (Figure 8 ). This interaction was detected because the likelihood of activity peak $\geq 80$ at PGSE tended to increase for heifers in Q2 and Q3 for GDPR as GHCR increased, but the opposite trend was observed for heifers in Q1 and Q4 for GDPR. It is important to note, however, that the main effect of GDPR was $(P<0.01)$ associated with the probability of activity peak $\geq 80$ at PGSE $(\mathrm{Q} 1=69.9 \pm 4.4, \mathrm{Q} 2=$ $87.1 \pm 3.4, \mathrm{Q} 3=79.5 \pm 3.3$, and $\mathrm{Q} 4=86.6 \pm 3.6 \%)$ because heifers in $\mathrm{Q} 1$ were $(P \leq 0.03)$ less likely to have activity peak $\geq 80$ at PGSE than heifers in Q2 and Q4. The estrous cycle phase on the day of $\mathrm{PGF}_{2 \alpha}$ treatment was (linear: $0.36 \pm 0.11, P<0.01$; quadratic: $-0.009 \pm$ $0.004, P=0.03)$ positively associated with likelihood of activity peak $\geq 80$.

Genomic merit for DPR (Q1 $=83.8 \pm 3.0, \mathrm{Q} 2=86.9$ $\pm 2.6, \mathrm{Q} 3=85.9 \pm 2.7$, and $\mathrm{Q} 4=87.9 \pm 2.4 \% ; P=$ $0.73), \mathrm{GHCR}(\mathrm{Q} 1=87.3 \pm 2.5, \mathrm{Q} 2=81.0 \pm 3.0, \mathrm{Q} 3=$ $86.2 \pm 2.6$, and $\mathrm{Q} 4=89.3 \pm 2.3 \% ; P=0.13)$, and the interaction between GDPR and GHCR $(P=0.71)$ were not associated with the likelihood of heat index $\geq 80$ on the day of PGSE. The estrous cycle day was (linear: $0.35 \pm 0.13, P<0.01$; quadratic: $-0.009 \pm 0.005, P=$ $0.08)$ positively associated with the likelihood of heat index $\geq 80$ on the day of PGSE.

\section{Association Among GDPR and GHCR and Reproductive Performance}

Genomic merit for DPR was $(P=0.04)$ associated with the likelihood of pregnancy $38 \pm 3 \mathrm{~d}$ after the first AI, but GHCR $(P=0.84)$ and the interaction between GDPR and GHCR $(P=0.37)$ were not associated with the likelihood of pregnancy $38 \pm 3 \mathrm{~d}$ after the first AI (Table 1$)$. The technician who conducted the AI $(P=$ $0.01)$ and the day of the estrous cycle at $\mathrm{PGF}_{2 \alpha}$ treatment (linear: $0.18 \pm 0.07, P=0.01$; quadratic: -0.004 $\pm 0.002, P=0.10$ ) were associated with the likelihood of pregnancy $38 \pm 3 \mathrm{~d}$ after the first AI. Genomic merit for DPR was $(P=0.05)$ associated with the likelihood of pregnancy $73 \pm 3 \mathrm{~d}$ after the first AI, but GHCR ( $P$ $=0.67)$ and the interaction between GDPR and GHCR $(P=0.48)$ were not associated with the likelihood of pregnancy $73 \pm 3 \mathrm{~d}$ after the first AI (Table 1). The technician who conducted the AI $(P=0.01)$ and the day of the estrous cycle at $\mathrm{PGF}_{2 \alpha}$ treatment (linear: $0.06 \pm 0.02, P<0.01)$ were associated with the likelihood of pregnancy $73 \pm 3 \mathrm{~d}$ after the first AI. Genomic merit for DPR $(P=0.78)$, GHCR $(P=0.69)$, and the

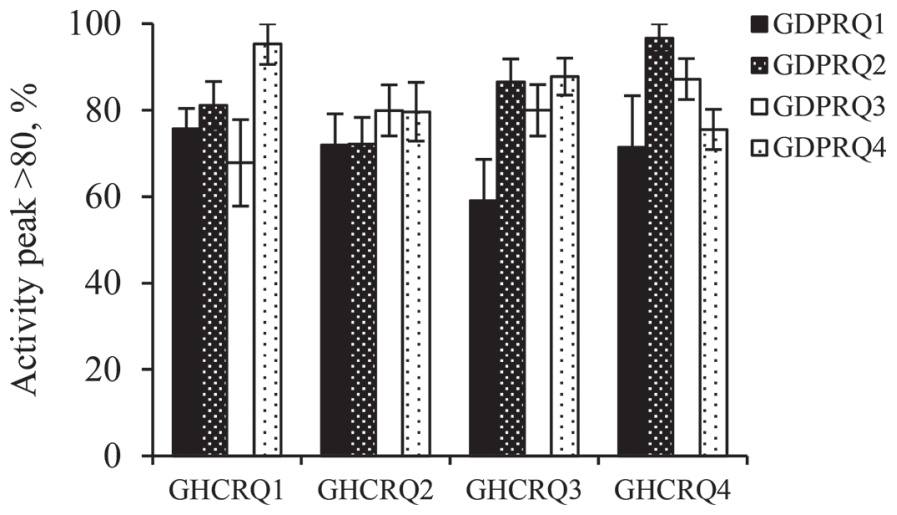

Figure 8. Probability of activity peak $\geq 80$ at $\mathrm{PGF}_{2 \alpha}$-synchronized estrus (PGSE) according to genomic merit for daughter pregnancy rate (GDPR) and genomic merit for heifer conception rate (GHCR). GDPR: Q1 $=-1.8$ to $0.8, \mathrm{Q} 2=0.9$ to $1.7, \mathrm{Q} 3=1.8$ to 2.5 , and $\mathrm{Q} 4$ $=2.6$ to 5.9. GHCR: $\mathrm{Q} 1=-2.1$ to $0.6, \mathrm{Q} 2=0.7$ to $1.4, \mathrm{Q} 3=1.5$ to 2.1 , and $\mathrm{Q} 4=2.2$ to 5.5. Effects of GDPR $(P<0.01)$, GHCR $(P=$ $0.27)$, and the interaction between GDPR and GHCR $(P=0.04)$. $\mathrm{Q}=$ quartile (Q1 = lowest, Q4 = highest). Error bars represent the SEM.

interaction between GDPR and GHCR $(P=1.00)$ were not associated with pregnancy loss from $38 \pm 3$ to $73 \pm$ $3 \mathrm{~d}$ after the first AI (overall average $=6.2 \%$ ).

Although GHCR was $(P<0.01)$ associated with the likelihood of pregnancy $38 \pm 3 \mathrm{~d}$ after the second AI, GDPR $(P=0.68)$ and the interaction between GDPR and GHCR $(P=0.83)$ were not associated with the likelihood of pregnancy $38 \pm 3 \mathrm{~d}$ after the second AI (Table 1). The PctTHI72 from d 30 to 60 was (linear: $3.45 \pm 1.98, P=0.08$; quadratic: $-4.13 \pm 1.77, P=$ $0.02)$ associated with the likelihood of pregnancy 38 $\pm 3 \mathrm{~d}$ after the second AI. Similarly, GHCR was $(P=$ 0.01 ) associated with the likelihood of pregnancy $73 \pm$ $3 \mathrm{~d}$ after the second AI, and GDPR $(P=0.80)$ and the interaction between GDPR and GHCR $(P=0.74)$ were not associated with the likelihood of pregnancy $73 \pm 3$ $\mathrm{d}$ after the second AI (Table 1). The PctTHI72 from d 30 to 60 was (linear: $2.71 \pm 1.97, P=0.17$; quadratic: $-3.56 \pm 1.77, P=0.04)$ associated with the likelihood of pregnancy $73 \pm 3 \mathrm{~d}$ after the second AI. The GDPR $(P=0.86)$, GHCR $(P=0.82)$, and the interaction between GDPR and GHCR $(P=1.00)$ were not associated with pregnancy loss from $38 \pm 3$ to $73 \pm 3 \mathrm{~d}$ after the second AI (overall average $=5.7 \%$ ).

Genomic merit for DPR (Q1 $=60.8 \pm 4.8$, Q2 $=$ $67.5 \pm 4.6, \mathrm{Q} 3=61.8 \pm 5.1$, and $\mathrm{Q} 4=71.5 \pm 4.8 \%$; $P=0.38$ ) was not associated with the likelihood of pregnancy after the first and second AI. We observed, however, that GHCR tended $(P=0.08)$ to be associated with the likelihood of pregnancy after the first and second AI because heifers in Q1 $(58.7 \pm 4.8 \%)$ tended $(P=0.07)$ to be less likely to be pregnant after the 
ESTROUS CHARACTERISTICS AND FERTILITY IN HOLSTEIN HEIFERS

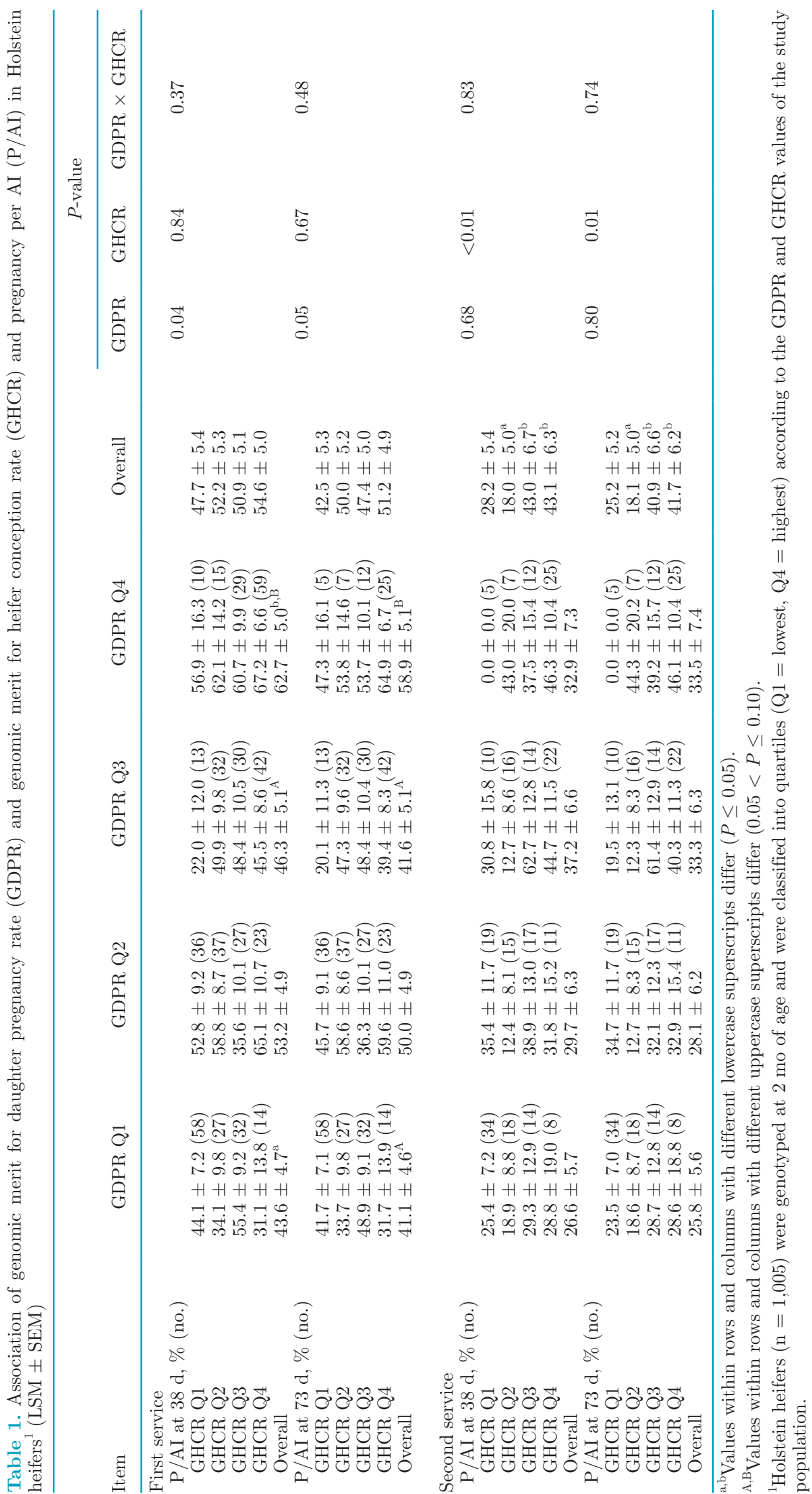


first and second AI than heifers in Q4 $(73.7 \pm 3.9 \%)$, but heifers in Q2 $(61.4 \pm 4.8 \%)$ and Q3 $(66.7 \pm 4.6 \%)$ did not $(P \geq 0.19)$ differ from each other and from heifers in Q1 and Q4. The interaction between GDPR and GHCR $(P=0.41)$ was not associated with the likelihood of pregnancy after the first and second AI. The PctTHI72 from d 0 to 30 was (linear: $2.46 \pm 1.57$, $P=0.12$; quadratic: $-2.89 \pm 1.41, P=0.04)$ associated with the likelihood of pregnancy after the first and second AI.

Genomic merit for DPR $(P=0.72)$ was not associated with the hazard of pregnancy up to $80 \mathrm{~d}$ after enrollment. Genomic merit for GHCR was $(P=0.05)$ associated with the hazard of pregnancy up to $80 \mathrm{~d}$ after enrollment because heifers in Q1 had (AHR = $0.65,95 \% \mathrm{CI}=0.48-0.88 ; P<0.01)$ reduced hazard of pregnancy compared with heifers in Q4, but heifers in Q2 $(\mathrm{AHR}=0.84,95 \% \mathrm{CI}=0.62-1.14)$ and Q3 (AHR $=0.78,95 \% \mathrm{CI}=0.58-1.05)$ did not $(P \geq 0.11)$ differ from each other and from heifers in Q1 and Q4. The interaction between GDPR and GHCR $(P=0.70)$ was not associated with the hazard of pregnancy up to 80 $\mathrm{d}$ after enrollment. The PctTHI72 from d 0 to 30 was (linear: $-0.32 \pm 0.14, P=0.02$ ) negatively associated with the hazard of pregnancy up to $80 \mathrm{~d}$ after enrollment, whereas estrous cycle day at enrollment tended to be (linear: $0.017 \pm 0.009, P=0.07$ ) positively associated with the hazard of pregnancy up to $80 \mathrm{~d}$ after enrollment. Genomic merit for HCR was not $(P=0.15)$ associated with the interval from the start of the reproductive program to pregnancy (mean \pm SEM interval from enrollment to pregnancy: $\mathrm{Q} 1=37.4 \pm 3.0$, Q2 $=$ $35.9 \pm 3.1, \mathrm{Q} 3=30.3 \pm 2.7$, and $\mathrm{Q} 4=28.9 \pm 2.6 \mathrm{~d}$; percentage of heifers censored at $80 \mathrm{~d}$ after enrollment: $\mathrm{Q} 1=32.5, \mathrm{Q} 2=24.6, \mathrm{Q} 3=27.4$, and $\mathrm{Q} 4=16.3 \%$ ). According to univariate analyses, GDPR and GHCR were not $(P \geq 0.33)$ associated with pregnancy per ET at $38 \pm 3$ and $75 \pm 3 \mathrm{~d}$ after estrus and were not $(P \geq$ 0.58 ) associated with hazard of pregnancy up to $80 \mathrm{~d}$ after enrollment for heifers receiving only ET.

\section{DISCUSSION}

The objectives of the current study were to establish the associations between genomic merit for female reproductive traits commonly used for the selection of dairy cattle, namely DPR and HCR, and characteristics of SPE and PGSE and pregnancy per service of Holstein heifers. Heifer conception rate estimates the likelihood of the daughter of a bull to conceive following AI compared with the population but it does not take into consideration estrous expression and estrous characteristics. Daughter pregnancy rate estimates the hazard of pregnancy after calving (21-d pregnancy rate, days open) of the daughter of a bull compared with the population. Therefore, DPR estimates are not based on heifer phenotypes. We used GDPR in the current study because, in addition to HCR and cow conception rate, it is used in the calculation of net merit (VanRaden, 2017). Additionally, hazard of pregnancy after calving is dependent on health (Ribeiro et al., 2016) and resumption of ovarian cycles (Chebel and Santos, 2010) postpartum, estrus detection accuracy and efficiency (Chebel et al., 2006), and the likelihood of pregnancy after an insemination. Therefore, we hypothesized that DPR is the fertility trait that would most likely be associated with estrous behavior. By using heifers and AED to investigate the associations between GDPR and estrous characteristics, we eliminated confounding due to health and time to resumption of ovarian cycles postpartum.

Genomic merit for HCR was negatively associated with duration of SPE, and the likelihood of activity peak $\geq 80$ at SPE was reduced for heifers with high GHCR (Q3 and Q4) and low GDPR (Q1). Conversely, GDPR was positively associated with duration of PGSE and was negatively associated with rumination nadir at PGSE. The interaction between GDPR and GHCR was associated with the likelihood of activity peak $\geq 80$ at PGSE but, more importantly, GDPR was positively associated with the likelihood of activity peak $\geq 80$ at PGSE. In a companion paper (Veronese et al., 2018), we determined from a subset of the heifers used in the current study that those with high GDPR had greater estradiol concentration within $24 \mathrm{~h}$ after onset of PGSE and larger ovulatory follicles, but GHCR was not associated with estradiol concentration and ovulatory follicle diameter. Estradiol triggers estrous behavior (Reith and Hoy, 2018) and has been positively associated with the duration of estrus (Aungier et al., 2015) and heat index (Madureira et al., 2015) of lactating cows. Additionally, mice treated with estradiol benzoate had reduced feed intake compared with an untreated control (Butera et al., 2010), which is believed to be mediated by decreased neuropeptide-Y secretion (Bonavera et al., 1994) and the cholecystokinin satiety systems, which are associated with residual feed intake and DMI in cattle (Abo-Ismail et al., 2013). Therefore, the positive associations between GDPR and estrous characteristics may be a consequence of greater steroidogenesis capacity by the ovarian follicles or reduced catabolism of steroids in the liver (Ferraretto et al., 2014), although the latter is less likely because only heifers, which have reduced DMI compared with lactating cows, were used in the current study. The negative association between GHCR and duration of SPE is more difficult to explain 
because no additional information regarding estradiol concentration and follicle development pre-SPE was collected from heifers in the current study. On d 13 of the estrous cycle, cows in the bottom $5 \%$ of genetic merit for calving interval (i.e., low fertility) had endometrial mRNA expression of genes associated with greater $\mathrm{PGF}_{2 \alpha}$ synthesis and secretion compared with cows in the top $20 \%$ of genetic merit for calving interval (i.e., high fertility), whereas the corpus luteum mRNA expression of genes indicated that low-fertility cows had greater response to $\mathrm{PGF}_{2 \alpha}$ and reduced steroidogenesis compared with high-fertility cows (Moore et al., 2016). If the upregulation of genes related to $\mathrm{PGF}_{2 \alpha}$ synthesis and secretion results in higher $\mathrm{PGF}_{2 \alpha}$ concentrations, one could expect that low-fertility cattle (including heifers in the lowest quartiles for GHCR) would have shorter and not longer estrus. Prostaglandins are in part responsible for ovulation in several species (reviewed by Fortune et al., 2009). Leonardi et al. (2012) demonstrated that treatment of prepubertal (no corpus luteum present) Angus heifers with $\mathrm{PGF}_{2 \alpha}$ resulted in $78.6 \%$ of them ovulating within $96 \mathrm{~h}$ compared with $7 \%$ of untreated controls. Thus, mRNA expression of genes corresponding to greater endometrial $\mathrm{PGF}_{2 \alpha}$ synthesis and secretion and greater corpus luteum response to $\mathrm{PGF}_{2 \alpha}$ among cattle with low genetic merit for fertility traits would be expected to result in hastened ovulation following the onset of estrus, resulting in shorter SPE. In fact, Cummins et al. (2012b) observed a shorter interval from peak activity to ovulation in low-fertility cows compared with high-fertility cows despite no differences in peak estradiol concentration. Additional studies are necessary to clearly characterize and elucidate the association between GHCR and estrous characteristics. The differences in characteristics of estrus according to GDPR and GHCR demonstrated herein are important because these characteristics are generally associated with mounting activity, vaginal mucus consistency, and uterine tone (Pahl et al., 2015; Silper et al., 2015) and may affect estrus detection efficiency and accuracy. In fact, in the current study, GDPR was positively associated with the hazard of estrus within $7 \mathrm{~d}$ of the first $\mathrm{PGF}_{2 \alpha}$ treatment and within $14 \mathrm{~d}$ of the start of the reproductive program.

The associations between genomic merit for milk yield and rumination nadir at SPE and interval from onset of SPE to peak activity are noteworthy because they demonstrate that intense selection for milk yield alone may in fact have detrimental effects on estrous expression. In fact, in the current study we demonstrated that genomic merit for milk yield was negatively associated with hazard of estrus (within $7 \mathrm{~d}$ of $\mathrm{PGF}_{2 \alpha}$ treatment and within $14 \mathrm{~d}$ of the start of the reproductive pro- gram). Pollott and Coffey (2008) demonstrated that cows that were daughters of sires with the highest PTA for fat and protein had delayed resumption of ovarian cycles postpartum, reduced $\mathrm{P} / \mathrm{AI}$ to first estrus, and increased incidence of silent estrus compared with cows that were daughters of sires with average PTA for fat and protein. Lopez et al. (2005) demonstrated that high-producing cows $(\geq 39.5 \mathrm{~kg} / \mathrm{d})$ had estrus that was $4.7 \mathrm{~h}$ shorter, 2.5 fewer mounts per estrus, and 6.5 fewer seconds of total standing time per estrus compared with low-producing cows $(<39.5 \mathrm{~kg} / \mathrm{d})$. Snijders et al. (2001) demonstrated that cows with high genetic merit for production traits (fat, protein, and yield) had reduced $\mathrm{P} / \mathrm{AI}$ compared with cows with medium genetic merit. We are unaware of other studies in which the association between genomic merit for milk yield and estrous characteristics and expression were investigated in dairy heifers. Our results suggest that selection of dairy cattle should be based on a more encompassing index (e.g., net merit) instead of isolated traits to prevent antagonistic effects. In the study population, there was a negative correlation between fertility traits, particularly DPR, and genomic merit for milk yield. In the US Holstein population, this trend has been mostly reversed since 2010 (Council on Dairy Cattle Breeding, 2018a). Similarly, the most recent young sires data from the Council on Dairy Cattle Breeding (2018b) suggest that genomic selection programs have succeeded in selecting animals superior for both genomic merit for milk yield and DPR.

In the current study, GDPR was positively associated with pregnancy to first AI. Kuhn et al. (2006) demonstrated that parent-average DPR was positively associated with $\mathrm{P} / \mathrm{AI}$ of heifers of multiple breeds. We speculate that the increased estradiol concentration within $24 \mathrm{~h}$ of the onset of PGSE among heifers with high GDPR (Veronese et al., 2018) may have affected oocyte quality, uterine environment, and the apparatus involved in maternal recognition of pregnancy. Bridges et al. (2012) demonstrated that treatment with estradiol before ovulation downregulated the expression of estradiol receptor $\alpha$ and progesterone receptor genes in the endometrium on d 15.5 of the estrous cycle, which is believed to affect the uterine environment. Ovariectomized cows receiving ET and treated with estradiol before GnRH-induced LH surge were more likely to have elevated pregnancy-specific protein concentration on estrous cycle d 24 (Madsen et al., 2015). Expression of signs of estrus at the end of an ovulation synchronization protocol was associated with expression of genes in the endometrium, corpus luteum, and conceptus 19 $\mathrm{d}$ after AI associated with local immune system, adhesion of endometrium epithelial cells and the conceptus, 
$\mathrm{PGF}_{2 \alpha}$ synthesis, and apoptosis (Davoodi et al., 2016). In a recent study, cows with greater concentrations of estradiol around the time of ovulation had upregulation of genes associated with facilitated glucose transport in the caruncular and intercaruncular tissues, which may represent a new pathway through which estradiol modulates uterine environment and pregnancy establishment (Northrop et al., 2018). Genomic merit for HCR was positively associated with pregnancy to second AI and tended to be positively associated with the hazard of pregnancy up to $80 \mathrm{~d}$ after enrollment. Because HCR has been implemented more recently in the genetic selection for dairy cattle, its true association with $\mathrm{P} / \mathrm{AI}$ is less understood. Ortega et al. (2016) evaluated 69 SNP related to fertility traits in Holstein cattle and showed that a significant number of genes associated with DPR were associated with HCR. Thus, it is likely that at least part of the genes driving fertility outcomes in cows associated with GDPR are the same driving fertility in heifers associated with GHCR. The role of fertility traits in reproductive physiology and biology has also been studied in populations of Irish and Australian cows (Cummins et al., 2012a,b; Moore et al., 2016). Irish cows with $>75 \%$ Holstein genetic ancestry in the bottom 5\% in genetic merit for calving interval had reduced duration of estrus, reduced activity during estrus, reduced postovulatory progesterone concentration, and reduced $\mathrm{P} / \mathrm{AI}$ compared with cows in the top $20 \%$ of genetic merit for calving interval (Cummins et al., 2012a,b). These results indicate that cattle with reduced genetic merit for fertility traits are more likely to have suboptimal preovulatory and postovulatory hormonal profile and gene expression profile in the endometrium and corpus luteum that may impair pregnancy establishment and maintenance.

\section{CONCLUSIONS}

In the current study, heifers in the highest quartile for GDPR had longer PGSE, and lower rumination nadir at PGSE, faster onset of estrus after a $\mathrm{PGF}_{2 \alpha}$ treatment and were more likely to become pregnant after the first AI. These results indicate that genetic selection for dairy cattle based on DPR has the potential to improve reproductive performance by possibly increasing insemination rate and pregnancy establishment and maintenance. Conversely, selection for dairy cattle based on GHCR should be carefully evaluated because, in the current study, heifers in the highest quartile for GHCR were more likely to become pregnant after the second $\mathrm{AI}$ and tended to have greater hazard of pregnancy, but they had shorter SPE, which may negatively affect insemination rates and overall repro- ductive performance. Finally, the negative associations between genomic merit for milk yield and estrous characteristics and hazard of estrus in heifers demonstrate that intense genetic selection for milk yield, irrespective of fertility traits, may affect reproductive performance independent of the actual milk yield. The external validity of the current study is limited considering that we conducted it in 1 herd in the southeastern United States. The range of GDPR of the heifers used in this study was -1.8 to 5.9 , whereas the range of GDPR for young sires is -5.5 to 5.9 (Council on Dairy Cattle Breeding, 2018b). As such, it is possible that differences in estrous characteristics in the US dairy population are more dramatic because the spread in GDPR in the current study was 7.7 compared with 11.4 in young sires. Furthermore, we could not determine how different environmental and management conditions could affect the outcomes evaluated herein and the associations between genotypes and phenotypes. Nonetheless, the use of AED devices provides consistency in how estrous characteristics were recorded, which will allow others to replicate the study in other conditions.

\section{ACKNOWLEDGMENTS}

The authors thank the owner and staff of North Florida Holsteins (Bell, FL) for their support during the course of this study. Our gratitude is extended to Merck Animal Health (Madison, NJ) and SCR Inc. (Netanya, Israel) for partial financial support.

\section{REFERENCES}

Abo-Ismail, M. K., M. J. Kelly, E. J. Squires, K. C. Swanson, S. Bauck, and S. P. Miller. 2013. Identification of single nucleotide polymorphisms in genes involved in digestive and metabolic processes associated with feed efficiency and performance traits in beef cattle. J. Anim. Sci. 91:2512-2529. https://doi.org/10.2527/ jas.2012-5756.

Aungier, S. P. M., J. F. Roche, P. Duffy, S. Scully, and M. A. Crowe. 2015. The relationship between activity clusters detected by an automatic activity monitor and endocrine changes during the periestrous period in lactating dairy cows. J. Dairy Sci. 98:1666-1684. https://doi.org/10.3168/jds.2013-7405.

Bonavera, J. J., M. G. Dube, P. S. Kalra, and S. P. Kalra. 1994. Anorectic effects of estrogen may be mediated by decreased neuropeptide- $Y$ release in the hypothalamic paraventricular nucleus. Endocrinology 134:2367-2370.

Bridges, G. A., M. L. Mussard, J. L. Pate, T. L. Ott, T. R. Hansen, and M. L. Day. 2012. Impact of preovulatory estradiol concentrations on conceptus development and uterine gene expression. Anim. Reprod. Sci. 133:16-26. https://doi.org/10.1016/j .anireprosci.2012.06.013.

Burnett, T. A., A. M. L. Madureira, B. F. Silper, A. C. C. Fernandes, and R. L. A. Cerri. 2017. Integrating an automated activity monitor into an artificial insemination program and the associated risk factors affecting reproductive performance of dairy cows. J. Dairy Sci. 100:5005-5018. https://doi.org/10.3168/jds.2016-12246.

Butera, P. C., D. M. Wojcik, and S. J. Clough. 2010. Effects of estradiol on food intake and meal patterns for diets that differ in flavor 
and fat content. Physiol. Behav. 99:142-145. https://doi.org/10 .1016/j.physbeh.2009.10.009.

Chebel, R. C., and J. E. Santos. 2010. Effect of inseminating cows in estrus following a presynchronization protocol on reproductive and lactation performances. J. Dairy Sci. 93:4632-4643. https:// doi.org/10.3168/jds.2010-3179.

Chebel, R. C., J. E. Santos, R. L. Cerri, H. M. Rutigliano, and R. G. Bruno. 2006. Reproduction in dairy cows following progesterone insert presynchronization and resynchronization protocols. J. Dairy Sci. 89:4205-4219.

Council on Dairy Cattle Breeding. 2018a. Genetic and phenotypic trend. Accessed Jan. 2019. https://queries.uscdcb.com/eval/ summary/trend.cfm.

Council on Dairy Cattle Breeding. 2018b. Young bull lists. Accessed Jan. 2019. https://queries.uscdcb.com/eval/summary/activeai menu.cfm.

Cummins, S. B., P. Lonergan, A. C. Evans, D. P. Berry, R. D. Evans, and S. T. Butler. 2012a. Genetic merit for fertility traits in Holstein cows: I. Production characteristics and reproductive efficiency in a pasture-based system. J. Dairy Sci. 95:1310-1322. https://doi.org/10.3168/jds.2011-4742.

Cummins, S. B., P. Lonergan, A. C. O. Evans, and S. T. Butler. 2012b. Genomic merit for fertility traits in Holstein cows: II. Ovarian follicular and corpus luteum dynamics, reproductive hormones, and estrus behavior. J. Dairy Sci. 95:3698-3710. https://doi.org/10 .3168/jds.2011-4976.

Davoodi, S., R. F. Cooke, A. C. C. Fernandes, B. I. Cappellozza, J. L. M. Vasconcelos, and R. L. A. Cerri. 2016. Expression of estrus modifies the gene expression profile in reproductive tissues on Day 19 of gestation in beef cows. Theriogenology 85:645-655. https:// doi.org/10.1016/j.theriogenology.2015.10.002.

Ferraretto, L. F., H. Gencoglu, K. S. Hackbart, A. B. Nascimento, F. Dalla Costa, R. W. Bender, J. N. Guenther, R. D. Shaver, and M. C. Wiltbank. 2014. Effect of feed restriction on reproductive and metabolic hormones in dairy cows. J. Dairy Sci. 97:754-763. https: //doi.org/10.3168/jds.2013-6925.

Fortune, J. E., E. L. Willis, P. J. Bridges, and C. S. Yang. 2009. The periovulatory period in cattle: Progesterone, prostaglandins, oxytocin and ADAMTS proteases. Anim. Reprod. 6:60-71.

Fricke, P. M., P. D. Carvalho, J. O. Giordano, A. Valenza, G. Lopes, and M. C. Amundson. 2017. Expression and detection of estrus in dairy cows: The role of new technologies. Animal 8(Suppl. S1):134-143. https://doi.org/10.1017/S1751731114000299.

García-Ruiz, A., J. B. Cole, M. Paul, G. R. Wiggans, F. J. Ruiz-López, and P. Curtis. 2016. Changes in genetic selection differentials and generation intervals in US Holstein dairy cattle as a result of genomic selection. Proc. Natl. Acad. Sci. USA 113:E3995-E4004. https://doi.org/10.1073/pnas.1611570113.

Giordano, J. O., A. S. Kalantari, P. M. Fricke, M. C. Wiltbank, and V. E. Cabrera. 2012. A daily herd Markov-chain model to study the reproductive and economic impact of reproductive programs combining timed artificial insemination and estrus detection. J. Dairy Sci. 95:5442-5460. https://doi.org/10.3168/jds.2011-4972.

Ismael, A., E. Strandberg, M. Kargo, A. Fogh, and P. Løvendahl. 2015. Estrus traits derived from activity measurements are heritable and closely related to the time from calving to first insemination. J. Dairy Sci. 98:3470-3477. https://doi.org/10.3168/jds.2014-8940.

Kommadath, A., H. A. Mulder, A. A. C. De Wit, H. Woelders, M. A. Smits, B. Beerda, R. F. Veerkamp, A. C. J. Frijters, and M. F. W. Pas. 2010. Gene expression patterns in anterior pituitary associated with quantitative measure of oestrous behaviour in dairy cows. Animal 4:1297-1307. https://doi.org/10.1017/S1751731110000303.

Kommadath, A., M. F. W. Pas, and M. A. Smits. 2013. Gene coexpression network analysis identifies genes and biological processes shared among anterior pituitary and brain areas that affect estrous behavior in dairy cows. J. Dairy Sci. 96:2583-2595. https://doi .org/10.3168/jds.2012-5814.

Kommadath, A., H. Woelders, B. Beerda, H. A. Mulder, A. A. C. de Wit, R. F. Veerkamp, M. F. W. te Pas, and M. A. Smits. 2011. Gene expression patterns in four brain areas associate with quan- titative measure of estrous behavior in dairy cows. BMC Genomics 12:200-209. https://doi.org/10.1186/1471-2164-12-200.

Kuhn, M. T., J. L. Hutchison, and G. R. Wiggans. 2006. Characterization of Holstein heifer fertility in the United States. J. Dairy Sci. 89:4907-4920. https://doi.org/10.3168/jds.S0022-0302(06)72541 $-3$.

Leonardi, C. E., L. F. Pfeifer, M. I. Rubin, J. Singh, R. J. Mapletoft, G. A. Pessoa, A. M. Bainy, and C. A. Silva. 2012. Prostaglandin $\mathrm{F}_{2 \alpha}$ promotes ovulation in prepubertal heifers. Theriogenology 78:1578-1582. https://doi.org/10.1016/j.theriogenology.2012 .06 .030 .

Lima, F. S., E. S. Ribeiro, R. S. Bisinotto, L. F. Greco, N. Martinez, M. Amstalden, W. W. Thatcher, and J. E. P. Santos. 2013. Hormonal manipulations in the 5-day timed artificial insemination protocol to optimize estrous cycle synchrony and fertility in dairy heifers. J. Dairy Sci. 96:7054-7065. https://doi.org/10.3168/jds .2013-7093.

Lopez, H., D. Z. Caraviello, L. D. Satter, P. M. Fricke, and M. C. Wiltbank. 2005. Relationship between level of milk production and multiple ovulations in lactating dairy cows. J. Dairy Sci. 88:27832793. https://doi.org/10.3168/jds.S0022-0302(05)72958-1.

López-Gatius, F., P. Santolaria, I. Mundet, and J. L. Yániz. 2005. Walking activity at estrus and subsequent fertility in dairy cows. Theriogenology 63:1419-1429.

Lucy, M. C. 2001. Reproductive loss in high-producing dairy cattle: Where will it end? J. Dairy Sci. 84:1277-1293. https://doi.org/10 .3168/jds.S0022-0302(01)70158-0.

Madsen, C. A., G. A. Perry, C. L. Mogck, R. F. Daly, M. D. MacNeil, and T. W. Geary. 2015. Effects of preovulatory estradiol on embryo survival and pregnancy establishment in beef cows. Anim. Reprod. Sci. 158:96-103. https://doi.org/10.1016/j.anireprosci 2015.05.006.

Madureira, A. M., B. F. Silper, T. A. Burnett, L. Polsky, L. H. Cruppe, D. M. Veira, J. L. Vasconcelos, and R. L. Cerri. 2015. Factors affecting expression of estrus measured by activity monitors and conception risk of lactating dairy cows. J. Dairy Sci. 98:7003-7014. https://doi.org/10.3168/jds.2015-9672.

Moore, S. G., J. E. Pryce, B. J. Hayes, A. J. Chamberlain, K. E. Kemper, D. P. Berry, M. McCabe, P. Cormican, P. Lonergan, T. Fair, and S. T. Butler. 2016. Differentially expressed genes in endometrium and corpus luteum of Holstein cows selected for high and low fertility are enriched for sequence variants associated with fertility. Biol. Reprod. 94:19. https://doi.org/10.1095/biolreprod .115 .132951

Northrop, E. J., J. J. J. Rich, R. A. Cushman, A. K. McNeel, É. M. Soares, K. Brooks, T. E. Spencer, and G. A. Perry. 2018. Effects of preovulatory estradiol on uterine environment and conceptus survival from fertilization to maternal recognition of pregnancy. Biol. Reprod. 99:629-638. https://doi.org/10.1093/biolre/ioy086.

NRC. 2001. Nutrient Requirements of Dairy Cattle. 7th rev. ed. Natl. Acad. Sci., Washington, DC.

Ortega, M. S., A. C. Denicol, J. B. Cole, D. J. Null, and P. J. Hansen. 2016. Use of single nucleotide polymorphisms in candidate genes associated with daughter pregnancy rate for prediction of genomic merit for reproduction in Holstein cows. Anim. Genet. 47:288-297. https://doi.org/10.1111/age.12420.

Pahl, C., E. Hartung, K. Mahlkow-Nerge, and A. Haeussermann. 2015. Feeding characteristics and rumination time of dairy cows around estrus. J. Dairy Sci. 98:148-154. https://doi.org/10.3168/jds.2014 -8025 .

Pereira, M. H. C., M. C. Wiltbank, and J. L. M. Vasconcelos. 2016. Expression of estrus improves fertility and decreases pregnancy losses in lactating dairy cows that receive artificial insemination or embryo transfer. J. Dairy Sci. 99:2237-2247. https://doi.org/10 .3168/jds.2015-9903.

Pollott, G. E., and M. P. Coffey. 2008. The effect of genetic merit and production system on dairy cow fertility, measured using progesterone profiles and on-farm recording. J. Dairy Sci. 91:3649-3660. https://doi.org/10.3168/jds.2007-0913. 
Reith, S., and S. Hoy. 2018. Review: Behavioral signs of estrus and the potential of fully automated systems for detection of estrus in dairy cattle. Animal 12:398-407. https://doi.org/10.1017/ S1751731117001975.

Ribeiro, E. S., G. Gomes, L. F. Greco, R. L. A. Cerri, A. Vieira-Neto, P. L. J. Monteiro Jr., F. S. Lima, R. S. Bisinotto, W. W. Thatcher, and J. E. P. Santos. 2016. Carryover effect of postpartum inflammatory diseases on developmental biology and fertility in lactating dairy cows. J. Dairy Sci. 99:2201-2220. https://doi.org/10.3168/ jds.2015-10337.

Roelofs, J. B., F. J. C. M. Van Eerdenburg, N. M. Soede, and B. Kemp. 2005. Various behavioral signs of estrous and their relationship with time of ovulation in dairy cattle. Theriogenology 63:1366-1377. https://doi.org/10.1016/j.theriogenology.2004.07 .009 .

Silper, B. F., A. M. L. Madureira, M. Kaur, T. A. Burnett, and R. L. A. Cerri. 2015. Short communication: Comparison of estrus characteristics in Holstein heifers by 2 activity monitoring systems. J. Dairy Sci. 98:3158-3165. https://doi.org/10.3168/jds.2014-9185.
Snijders, S. E., P. G. Dillon, K. J. O'Farrell, M. Diskin, A. R. Wylie, D. O'Callaghan, M. Rath, and M. P. Boland. 2001. Genetic merit for milk production and reproductive success in dairy cows. Anim. Reprod. Sci. 65:17-31.

VanRaden, P. M. 2017. Net merit as a measure of lifetime profit: 2017 revision. Accessed Apr. 8, 2019. https://www.aipl.arsusda.gov/ reference/nmcalc-2017.htm.

VanRaden, P. M., A. H. Sanders, M. E. Tooker, R. H. Miller, and H. D. Norman. 2003. Daughter pregnancy rate evaluation of cow fertility. Accessed Apr. 8, 2019. https://aipl.arsusda.gov/reference/ fertility/DPR_rpt.htm.

Veronese, A., O. Marques, F. Peñagaricano, R. S. Bisinotto, K. G. Pohler, T. R. Bilby, and R. C. Chebel. 2018. Genomic merit for reproductive traits. II: Physiological responses of Holstein heifers. J. Dairy Sci. 102:6639-6648. https://doi.org/10.3168/jds.2018-15245.

Woelders, H., T. Van Der Lende, A. Kommadath, M. F. W. Pas, M. A. Smits, and L. M. T. E. Kaal. 2014. Central genomic regulation of the expression of oestrous behaviour in dairy cows: A review. Animal 8:754-764. https://doi.org/10.1017/S1751731114000342. 